\title{
Influence of Parenting Quality and Neuroticism on Perceived Job Stressors and Psychological and Physical Stress Response in Adult Workers from the Community
}

This article was published in the following Dove Press journal:

Neuropsychiatric Disease and Treatment

\author{
Tomoteru Seki $\mathbb{D}^{1,2}$ \\ Akiyoshi Shimura $\mathbb{D}^{\prime}$ \\ Hitoshi Miyama $\mathbb{D}^{1}$ \\ Wataru Furuichi ${ }^{1}$ \\ Kotaro Ono' \\ Jiro Masuya (1D) \\ Yuko Odagiri (iD ${ }^{3}$ \\ Shigeru Inoue $\mathbb{D}^{3}$ \\ Takeshi Inoue (D) \\ 'Department of Psychiatry, Tokyo \\ Medical University, Shinjuku-ku, Tokyo \\ 160-0023, Japan; ${ }^{2}$ Fuji Psychosomatic \\ Rehabilitation Institute Hospital, \\ Fujinomiya, Shizuoka 4l8-0035, Japan; \\ ${ }^{3}$ Department of Preventive Medicine and \\ Public Health, Tokyo Medical University, \\ Shinjuku-ku, Tokyo 160-8402, Japan
}

Correspondence: Akiyoshi Shimura

Department of Psychiatry, Tokyo Medical

University, 6-7-I Nishishinjuku, Shinjuku-ku,

Tokyo 160-0023, Japan

Tel +8I-3-3342-6III

Fax +8I-3-3340-4499

Email sim@tokyo-med.ac.jp
Background: The complex interaction between parenting styles, job stressors, and the stress response has not been clarified to date. We hypothesized that neuroticism acts as a mediator in the effects of parenting quality on perceived job stressors and the psychological and physical stress response (PPSR), and tested this hypothesis using covariance structure analysis.

Subjects and Methods: We conducted research between April 2017 and April 2018 on 597 adult from the community, and 69 subjects were excluded owing to missing data or nonworkers. Finally, a total of 528 participants were analyzed using the following selfadministered questionnaires: the Parental Bonding Instrument, the shortened Eysenck Personality Questionnaire-Revised, and the Brief Job Stress Questionnaire (BJSQ). The data were analyzed by single regression analyses and covariance structure analyses. Job stress was assessed by the BJSQ and 2 subscales, ie, perceived job stressors and the PPSR. This study was approved by the Ethics Committee of Tokyo Medical University.

Results: On covariance structure analysis, high parental overprotection was associated with high neuroticism and high PPSR directly, but had no significant effect on perceived job stressors. High parental overprotection was associated with high-perceived job stressors and the high PPSR indirectly through enhanced neuroticism. High parental overprotection was also associated with the high PPSR indirectly through 2 combined paths of neuroticism and perceived job stressors. This model accounted for $40 \%$ of the variability of the PPSR. On the other hand, parental care had opposite effects to parental overprotection, and this model of parental care accounted for $39 \%$ of the variability of PPSR. The model fits of the 2 models were good.

Conclusion: Our results suggest that the quality of parenting in childhood is associated with perceived job stressors and the PPSR indirectly through neuroticism.

Keywords: parental care, parental overprotection, neuroticism, job stress, covariance structure analysis, structural equation model

\section{Introduction}

Job stress is caused by jobs that are not matched to a person's knowledge and abilities, involve pointless tasks, unpleasant duties, too much or too little work load, lack of interaction with colleagues, harassment, lack of communication, and conflicts between family life and work. ${ }^{1}$ Job stress is associated with depressive symptoms. $^{2}$ Burnout syndrome resulting from job stress is associated with 
musculoskeletal and cardiovascular diseases, and reduced life expectancy. ${ }^{3,4}$ In 1979, the job demand-control model, which shows that the combination of high job demand and low decision latitude is associated with high psychological distress, was proposed. ${ }^{5}$ Later, the job demand-control model was extended to the job demand-control support model to account for the role of workplace support as a third predictor. ${ }^{6,7}$ In 1988, the job stress model was established by the National Institute for Occupational Safety and Health (NIOSH), which showed that age, sex, marital status, personality traits, etc., affect acute reactions by job stressors. Based on this job stress model of the NIOSH, the Generic Job Stress Questionnaire (GJSQ), which is a self-completed job stress questionnaire, was developed after appropriate items (eg, physical environment) were selected. ${ }^{8}$ In Japan, job stress is also considered as a major risk factor for a wide range of health outcomes. ${ }^{9}$ In 1993, the Japanese version of the GJSQ was translated and confirmed to be sufficiently reliable and valid. ${ }^{10}$ The Brief Job Stress Questionnaire (BJSQ), which contains components similar to GJSQ, was developed referring to the job demand-control support model,${ }^{5}$ and is used in the stress check program in Japan. ${ }^{11-14}$ Following the amendment of the Industrial Safety and Health Law in 2014, the BJSQ has been used as the standard questionnaire in the stress check program, which has been compulsory since December 1, 2015, for business establishments with 50 or more workers. ${ }^{9}$

Personality traits, particularly neuroticism, have been reported to be associated with depressive symptoms in the general adult population. ${ }^{15-18}$ The association between neuroticism and job stress has also been reported. In recent years, studies have reported that neuroticism is more strongly associated with job stressors and burnout syndrome caused by job stressors than work-associated factors. ${ }^{19,20}$ These studies do not support the widespread idea of previous researchers that the psychosomatic stress response is primarily linked to work-contextualized factors and is only secondary to personality dispositional factors. ${ }^{20-22}$

Parenting styles are the child-rearing that children receive from their parents, which reflect the "bonding" between parents and children, and are closely associated with child development and the onset of mental illness in adulthood. ${ }^{23}$ Poor parenting styles and child abuse in childhood have been reported to affect depressive symptoms in adulthood. ${ }^{24-27}$ The association between parenting styles and neuroticism has also been reported. Certain personality traits (extraversion and neuroticism) have been shown to mediate the effects of parenting styles on depressive symptoms in the general adult population. ${ }^{15,18}$ In association with personality dispositional factors other than neuroticism, we reported that childhood abuse affects depressive symptoms in adulthood through affective temperaments (depressive, cyclothymic, irritable, and anxious). ${ }^{28}$ In addition, child abuse reportedly affects depressive symptoms in adulthood through specific attachment styles. ${ }^{29}$

There have been no studies to date showing the involvement of personality traits in the effects of parenting styles on job stressors and the stress response. Our recent studies reported that neuroticism mediates the effects of parenting styles and child abuse on the negative appraisal of adult life events and on adult depressive symptoms. ${ }^{17,18}$ These findings suggest that parenting styles may also affect job stressors and the resulting stress response through their effects on neuroticism. We hypothesized that neuroticism acts as a mediator of the effects of parenting quality on perceived job stressors and the psychological and physical stress response (PPSR), and verified this hypothesis in adult workers using structural equation modeling.

\section{Subjects and Methods Subjects}

Between April 2017 and April 2018, questionnaires and instructions of this study were distributed to 1,237 adults by convenience sampling through our acquaintances at Tokyo Medical University. A total of 640 subjects did not participate in this study, and 69 subjects were excluded due to missing data or nonworkers. A total of 528 subjects (233 men and 295 women, average age: $41.4 \pm 11.9$ years) who provided consent and fully valid responses were analyzed (Table 1). This study was part of a larger study, in which several questionnaires were investigated. ${ }^{30}$ In terms of occupational contracts, there were 452 regular employees, 6 contract or commission employees, 52 temporary or part-time employees, and 15 others (Table 2). Regarding job class, there were 381 general class employees, 65 sectional manager class employees, and 7 manager level or higher employees (Table 2). Employment status was 323 inflexible, 24 discretionary, 5 flexible, 26 shift work (not including night shift), 103 shift work (including night shift), and 2 others (Table 2). Overtime work (hours per month) was 20 hours or less in 351 workers, $21-40$ hours in 74 workers, 41-60 hours for 29 workers, and 61 hours or more in 
Table I Patient Characteristics, PBI, EPQ-R, and BJSQ Scores and Their Correlation with PPSR Scores of BJSQ or Effects on PPSR Score in Adult Workers

\begin{tabular}{|c|c|c|}
\hline Characteristic or Measure & $\begin{array}{l}\text { Value (Number or } \\
\text { Mean } \pm \text { SD) }\end{array}$ & $\begin{array}{l}\text { Correlation with PPSR Score }(r) \text { or Effect on } \\
\text { PPSR Score } \\
\text { (Mean } \pm \text { SD, } t \text {-test) }\end{array}$ \\
\hline Age (years) & $41.4 \pm 11.9$ & $r=-0.083, p=0.057$ \\
\hline Sex (men:women) & 233:295 & $\begin{array}{l}\text { Men: } 51.4 \pm 14.3 \text { vs women: } 55.9 \pm 14.5 \\
p<0.001 \text { (t-test) }\end{array}$ \\
\hline Education years & $14.7 \pm 1.8$ & $r=-0.059, p=0.178$ \\
\hline Marital status (married: unmarried) & $346: 178$ & $\begin{array}{l}\text { Married: } 52.1 \pm 14.2 \text { vs unmarried: } 57.5 \pm 14.9 \text {, } \\
p<0.001 \text { (t-test) }\end{array}$ \\
\hline Living alone (yes:no) & $105: 423$ & $\begin{array}{l}\text { Yes: } 56.2 \pm 15.2 \text { vs no: } 53.3 \pm 14.4 \\
p=0.068 \text { (t-test) }\end{array}$ \\
\hline Number of offspring & $1.4 \pm 1.3$ & $r=-0.062, p=0.155$ \\
\hline Comorbidity of physical disease (yes:no) & $104: 424$ & $\begin{array}{l}\text { Yes: } 54.7 \pm 14.6 \text { vs no: } 53.7 \pm 14.6 \\
p=0.554 \text { (t-test) }\end{array}$ \\
\hline $\begin{array}{l}\text { First-degree relative with psychiatric disease } \\
\text { (yes:no) } \\
\text { PBI } \\
\text { Paternal care } \\
\text { Maternal care } \\
\text { Paternal overprotection } \\
\text { Maternal overprotection }\end{array}$ & $\begin{array}{l}52: 425 \\
23.5 \pm 8.1 \\
28.1 \pm 6.9 \\
9.7 \pm 6.9 \\
9.6 \pm 6.9\end{array}$ & $\begin{array}{l}\text { Yes: } 55.2 \pm 13.7 \text { vs no: } 53.6 \pm 14.6, \\
p=0.449 \text { (t-test) } \\
r=-0.146, p=0.001 \\
r=-0.171, p<0.001 \\
r=0.212, p<0.001 \\
r=0.225, p<0.001\end{array}$ \\
\hline EPQ-R score & $4.4 \pm 3.5$ & $r=0.555, p<0.001$ \\
\hline $\begin{array}{l}\text { BJSQ } \\
\text { Perceived job stressors } \\
\text { PPSR }\end{array}$ & $\begin{array}{l}40.6 \pm 6.1 \\
53.9 \pm 14.6\end{array}$ & $r=0.413, p<0.001$ \\
\hline
\end{tabular}

Notes: Data are presented as means $\pm \mathrm{SD}$ or numbers; $R$, Pearson correlation coefficient.

Abbreviations: BJSQ, Brief Job Stress Questionnaire; EPQ-R, Eysenck Personality Questionnaire revised; PBI, Parental Bonding Instrument; PPSR, Psychological and physical stress response.

16 workers (Table 2). Demographic information and the 3 questionnaires were anonymously surveyed. Participation in this study was not mandatory, and subjects were informed that participation was completely voluntary, that there would be no penalty for not participating, and that the collected information would be anonymized so that the individuals cannot be identified. This study was approved by the Ethics Committee of Tokyo Medical University.

\section{Questionnaires}

\section{Parental Bonding Instrument (PBI)}

PBI is a retrospective self-administered questionnaire that measures how respondents evaluate their parents' childrearing, after they become adults. ${ }^{23}$ The PBI consists of 25 question items, which are classified into 2 subscales;
13 question items of overprotection ( $0-39$ points) and 12 question items of care ( $0-36$ points), and it is designed to be evaluated on a 4-point scale of "very likely (3 points)", "moderately likely (2 points)", "moderately unlikely (1 point)", and "very unlikely ( 0 points)". The PBI is performed separately for each father and mother. The total scores of overprotection and care of the father and the mother were used for analysis. The validity and reliability of the Japanese version of the PBI were confirmed. ${ }^{31}$

\section{Eysenck Personality Questionnaire-Revised (EPQ-R)}

The Eysenck Personality Questionnaire is a self-administered questionnaire that measures neuroticism, and was revised in 1985 to the Eysenck Personality Questionnaire-Revised (EPQ-R). ${ }^{32}$ The shortened version of the EPQ-R consists of 
Table 2 Effects of Occupational Contracts, Job Class, Employment Status, and Overtime Work Hours on PPSR Score of the BJSQ in Adult Workers

\begin{tabular}{|c|c|c|}
\hline Characteristic or Measure & Value & $\begin{array}{l}\text { Effect on PPSR Score } \\
(\text { Mean } \pm \text { SD) }\end{array}$ \\
\hline \multicolumn{3}{|l|}{ Occupational contract } \\
\hline Regular & 452 & $53.7 \pm 14.6$ \\
\hline Contract/commission & 6 & $59.5 \pm 18.1$ \\
\hline Temporary/part-time & 52 & $55.7 \pm 15.3$ \\
\hline \multirow[t]{2}{*}{ Others } & 15 & $50.8 \pm 10.9$ \\
\hline & & $F(3,521)=0.797 ; p=0.496$ \\
\hline \multicolumn{3}{|l|}{ Job class } \\
\hline General & 381 & $54.3 \pm 14.4$ \\
\hline Section manager class & 65 & $50.7 \pm 14.7$ \\
\hline \multirow[t]{2}{*}{ Manager level or higher } & 7 & $41.9 \pm 8.6$ \\
\hline & & $F(2,450)=4.013 ; p=0.019$ \\
\hline \multicolumn{3}{|l|}{ Employment status } \\
\hline Inflexible & 323 & $54.3 \pm 14.9 *$ \\
\hline Discretionary & 24 & $45.1 \pm 11.4$ \\
\hline Flexible & 5 & $46.4 \pm 10.9$ \\
\hline Shift work (not including night shift) & 26 & $57.4 \pm 16.0 *$ \\
\hline Shift work (including night shift) & 103 & $53.8 \pm 12.8$ \\
\hline \multirow[t]{2}{*}{ Others } & 2 & $32.5 \pm 2.1$ \\
\hline & & $F(5,477)=3.309 ; p=0.006$ \\
\hline \multicolumn{3}{|l|}{ Overtime work hours (/month) } \\
\hline$\leq 20$ hours & 351 & $54.1 \pm 13.7$ \\
\hline $21-40$ hours & 74 & $53.9 \pm 16.9$ \\
\hline $4 I-60$ hours & 29 & $52.8 \pm 15.6$ \\
\hline \multirow[t]{2}{*}{$\geq 61$ hours } & 16 & $54.3 \pm 17.6$ \\
\hline & & $F(3,466)=0.080 ; p=0.971$ \\
\hline
\end{tabular}

Notes: Data presented as means $\pm S D$ or numbers; One-way ANOVA followed by the Bonferroni test (post-hoc test); ${ }^{*} p<0.05$ vs Discretionary (Bonferroni test).

12 question items, and it is designed to be evaluated on a 2-point scale of "yes (1 point)" and "no (0 points)". The total score was used for analysis. The validity and reliability of the Japanese shortened version of the EPQ-R were confirmed by our previous study. ${ }^{33}$

\section{Brief Job Stress Questionnaire (BJSQ)}

The BJSQ is a self-administered questionnaire that assesses job stress, which was developed by Shimomitsu et al. ${ }^{11,14}$ The BJSQ consists of 57 question items, which are classified into the following 4 subscales: perceived job stressors, the PPSR, social support, and satisfaction, and it is designed to be evaluated on a 4-point scale (1 point to 4 points). In this study, 2 subscales of 17 question items, ie, perceived job stressors (17-68 points), such as quantitative job overload, qualitative job overload, physical demands, job control, skill utilization, interpersonal conflict, poor physical environment, suitable job, and meaningfulness of work, and 29 question items of the PPSR (29-116 points), such as lack of vigor, irritability, fatigue, anxiety, depression, and somatic responses, were evaluated and analyzed. The higher the score of each subscale, the higher the stress. The total scores of perceived job stressors and the PPSR were used for analysis. In the BJSQ, as evaluation of job stressors is a subjective evaluation, job stressors are described as "perceived" job stressors in this study.

\section{Structural Equation Model}

In this study, neuroticism was hypothesized as having a mediating role on the effects of parenting quality on perceived job stressors and the PPSR. Based on this assumption, a structural equation model was built using care or overprotection scores of the PBI, the total score of the EPQ-R, and perceived job stressors and PPSR scores of the BJSQ. The average scores of each subscale of the father and mother as observed variables in the PBI composed a latent variable of care or overprotection (Figure 1).

\section{Statistical Analysis}

For a comparison of demographic information and questionnaire data, the Pearson correlation coefficient was calculated, and the $t$-test or analysis of variance followed by the Bonferroni test was performed using SPSS Statistics Version 25 software (SPSS Inc., Chicago, IL, USA). We analyzed the structural equation model using covariance structure analysis with the robust maximum likelihood estimation method (Mplus version 8.0, Muthén \& Muthén, Los Angeles, CA, USA). In this study, the Comparative Fit Index (CFI) and Root Mean Square Error Approximation (RMSEA) were used as fit indices. A CFI of greater than 0.95 and a RMSEA of less than 0.08 were considered to indicate an acceptable fit, whereas a CFI of greater than 0.97 and a RMSEA of less than 0.05 were considered to indicate a good fit in this study. ${ }^{34}$ All coefficients of the covariance structure analysis were standardized.

\section{Results}

\section{Correlation of Basic Demographic Information of the Subjects and Data of Each Questionnaire with PPSR Scores of the BJSQ}

Table 1 shows the demographic characteristics and the scores of PBI, EPQ-R, and the BJSQ, and their correlation 

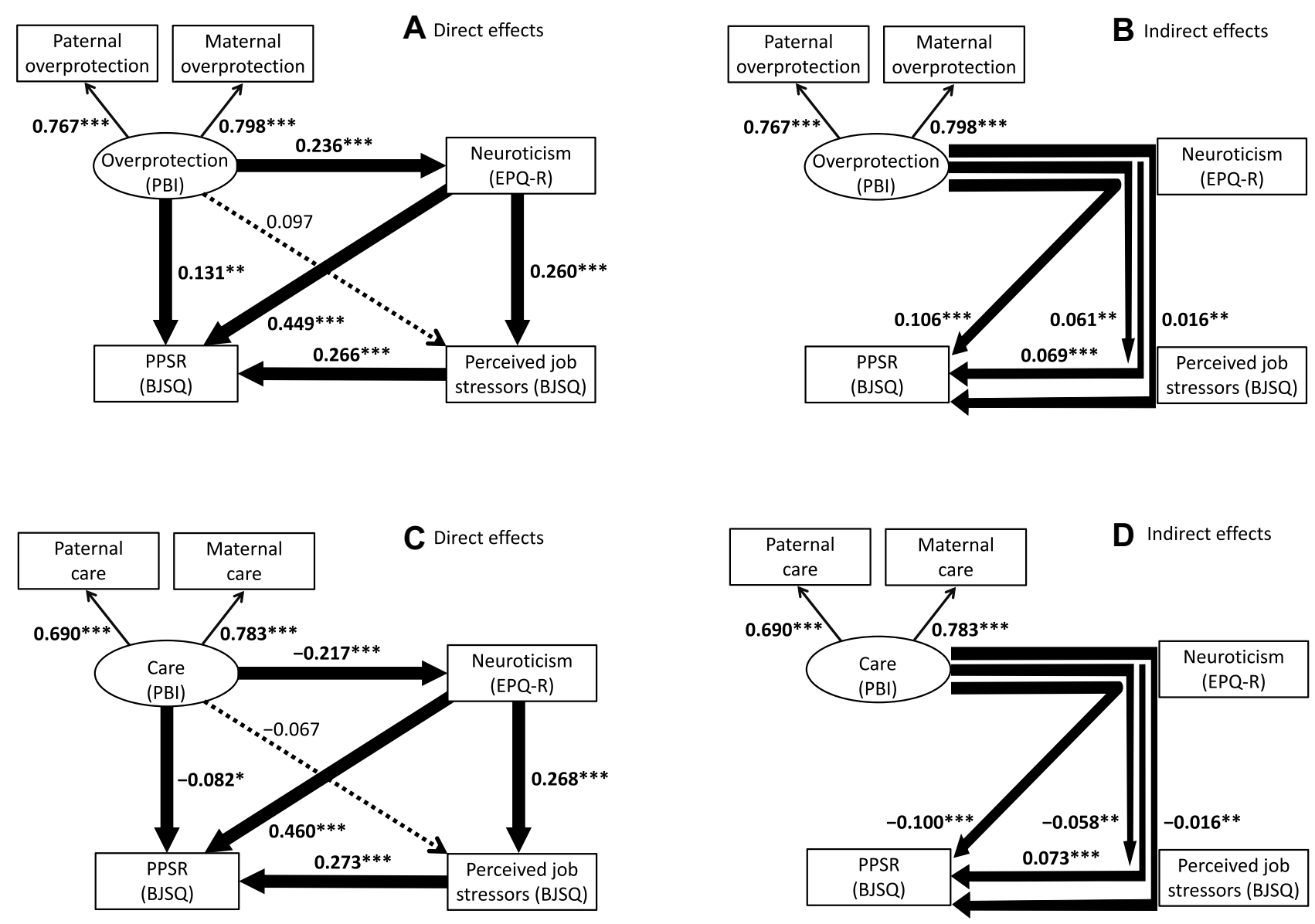

Figure I The results of direct (A and $\mathbf{C})$ and indirect (B and $\mathbf{D})$ effects of covariance structure analysis in the structural equation model with parental overprotection $(\mathbf{A}$ and $\mathbf{B})$ or parental care (C and $\mathbf{D})$, neuroticism, job stressors, and PPSR in 528 adult workers from the community. Ovals show latent variables and rectangles show observed variables. The solid arrows indicate the statistically significant pathways, and the dotted arrows ( $\mathbf{A}$ and $\mathbf{C})$ indicate the nonsignificant pathways. The numbers beside the arrows represent the $\operatorname{direct}(\mathbf{A}$ and $\mathbf{C})$ or indirect $(\mathbf{B}$ and $\mathbf{D})$ standardized coefficients. $*_{p}<0.05, * * p<0.01, * * * p<0.001$.

Abbreviations: BJSQ, Brief Job Stress Questionnaire; EPQ-R, Eysenck Personality Questionnaire revised; PBI, Parental Bonding Instrument; PPSR, Psychological and physical stress response.

with PPSR scores of the BJSQ or effects on the PPSR score in 528 adult workers. PPSR scores were higher in women and unmarried individuals. No other demographic data was associated with PPSR scores. Paternal care and maternal care were negatively correlated with PPSR scores; the higher the care in childhood, the lower the PPSR scores. Paternal overprotection and maternal overprotection were positively correlated with PPSR scores; the higher the childhood overprotection, the higher the PPSR scores. The EPQ-R scores were positively correlated with PPSR scores; the higher the neuroticism, the higher the PPSR scores. Perceived job stressors were moderately positively correlated with PPSR scores; the higher the perceived job stressor scores, the higher the PPSR scores.

Cronbach's $\alpha$ coefficients calculated for the individual subscales of the PBI were found to be 0.866 for overprotection from father, 0.920 for care from father, 0.873 for overprotection from mother, and 0.915 for care from mother and indicate excellent internal consistency. Cronbach's $\alpha$ coefficient calculated for the EPQ-R was 0.859, indicating excellent internal consistency. Cronbach's $\alpha$ calculated for the individual subscales of the BJSQ was found to be 0.740 for perceived job stressors and 0.909 for the PPSR and the latter indicates excellent internal consistency.

Table 2 shows the effects of occupational contracts, job class, employment status, and overtime work hours per month on PPSR scores of the BJSQ in 528 adult workers. Multiple comparison by the Bonferroni test of the factors that were statistically significant on ANOVA demonstrated that workers performing discretionary work had a significantly lower PPSR score than those performing inflexible and shift work (not including night-shift work). 
The association of other variables with the PPSR was not significant.

\section{Analysis of the Structural Equation Model} In the model of Figure 1A, the fit indices were CFI $=0.999$ and RMSEA $=0.021$, indicating a good fit. The standardized coefficients from latent variable "overprotection" to observed variables were similar; 0.767 for fathers and 0.798 for mothers. Overprotection had significant direct effects on neuroticism and the PPSR, but not on perceived job stressors. Neuroticism showed significantly positive direct effects on perceived job stressors and the PPSR. Perceived job stressors had a significantly positive direct effect on the PPSR.

Figure 1B shows the significant indirect effects of overprotection. Overprotection had significant indirect effects on perceived job stressors and the PPSR via neuroticism. Furthermore, high overprotection was significantly associated with the high PPSR via combined pathways involving both neuroticism and perceived job stressors. The indirect effect of overprotection on the PPSR via perceived job stressors was not significant (data not shown in Figure 1B, standardized path effect $=$ 0.071, $p=0.086$ ). High neuroticism was also associated with the high PPSR through perceived job stressors. The square of the multiple correlation coefficient of PPSR scores in this model was 0.396 , ie, this model explains $39.6 \%$ of the variability in the PPSR of adult workers.

In the model shown in Figure 1C, the fit indices were CFI $=1.000$ and RMSEA $=0.000$, indicating a good fit. The standardized coefficients from the latent variable "care" to the observed variables were 0.690 for the father and 0.783 for the mother; ie, the contribution of maternal care was larger than that of paternal care. Care had significant negative direct effects on neuroticism and the PPSR, but not on perceived job stressors. Neuroticism showed significant positive direct effects on perceived job stressors and the PPSR. Perceived job stressors had a significant positive direct effect on the PPSR.

Figure 1D shows significant indirect effects on care. Care had significant negative indirect effects on perceived job stressors and the PPSR via neuroticism. Furthermore, high care was significantly associated with low PPSR via combined pathways involving both neuroticism and perceived job stressors. The indirect effect of care on the PPSR via perceived job stressors was not significant (data not shown in Figure 1D, $-0.018, p=0.283$ ). High neuroticism was associated with the high PPSR through perceived job stressors. The square of the multiple correlation coefficient of PPSR scores in this model was 0.386 , ie, this model explains $38.6 \%$ of the variability in the PPSR of adult workers.

\section{Discussion}

To our knowledge, this study is the first report to suggest that the quality of parenting is indirectly associated with PPSR through effects on neuroticism and perceived job stressors, by performing covariance structure analysis on adult workers. Previous studies have reported associations between the quality of parenting and neuroticism and between neuroticism and job stress consequences. ${ }^{15,18-20}$ However, how the quality of parenting is associated with perceived job stressors and the PPSR through neuroticism has not been reported to date.

In a previous cross-sectional study, overprotection from fathers was found to indirectly affect depressive symptoms through neuroticism in male patients with depression. ${ }^{15}$ However, there was no mediating effects of neuroticism in women. On the other hand, in a previous study of general adult volunteers, including both men and women, parenting styles influenced the negative appraisal of adult life events and adult depressive symptoms via neuroticism. ${ }^{18}$ The results of these previous studies are consistent with the results of the present study, which suggest that high parental overprotection is associated with high-perceived job stressors and the high PPSR through neuroticism, and parental care has the opposite effect. Therefore, our present results support the hypothesis that poor child-rearing received from parents first enhances neuroticism and, after a long latent period, increases the sensitivity to stress and at the same time enhances the stress response. Conversely, behaviorally inhibited children may influence poor parenting styles (eg, overprotection) from parents. ${ }^{35}$ Considering our results, there is a possibility that poor child-rearing and children's neuroticism make a vicious cycle.

In the structural equation model of this study, perceived job stressors had a significant effect (0.266:1A, $0.273: 1 \mathrm{C}$ ) on the PPSR, but neuroticism had a stronger effect on the PPSR (0.449: $1 \mathrm{~A}, 0.460: 1 \mathrm{C})$ than perceived job stressors. The role of neuroticism has been reported in previous studies on job stress. For example, in the study of Lachowska et al, neuroticism had a greater effect on the symptoms of somatic disorders, anxiety, insomnia, functioning disorders, symptoms of depression, and global distress than work demands in working men or women 
raising children of up to 12 years of age. ${ }^{19}$ In a study by Bianchi et al using burnout at work as an index, neuroticism had a stronger effect on burnout than job stressors, which were evaluated by effort-reward imbalance. ${ }^{20}$ These previous studies are consistent with the results of our present study. However, these previous studies on the effects of neuroticism on job stress did not analyze the effects of neuroticism on job stressors or the indirect effects on the stress response. A new finding of the present study is that the association between these factors have become clear, indicating that high neuroticism is associated with the sensitivity of perceived job stressors and at the same time is associated with the high psychological and physical stress response.

In this study, the quality of parenting was not associated with perceived job stressors directly, but was associated with them through neuroticism. In our previous study of general adults, the quality of parenting did not affect the negative appraisal of adult life events directly, which included job stress, but indirectly affected stressors only through its effect on neuroticism. ${ }^{18}$ On the other hand, the quality of parenting had a direct effect on PPSR. This suggests a possible pathway for the effects of the quality of parenting on PPSR through factors other than neuroticism and perceived job stressors (family, other personal factors, and social support). Interestingly, job stress of the parents has been reported to adversely affect parents' attitudes toward their children, which adversely affect child adaptation indirectly. ${ }^{36}$ In other words, job stress may transmit psychological adverse effects from parents to the next generation through parenting and neuroticism.

The results of this study suggest that improving the quality of parenting may lead to a reduction in perceived job stressors and PPSR of the next generation, by reducing neuroticism in children, and consequently reducing medical expenses and improving presenteeism and absenteeism. On the other hand, intervention of neuroticism is also expected to improve job stress. It has been reported that intervention by improving workplace bullying status reduces neuroticism, and mindfulness and cognitive behavioral therapy also reduces neuroticism. ${ }^{37-39}$

\section{Limitations}

As this study is a cross-sectional study, we cannot conclude the causal association between the factors. Therefore, a prospective follow-up study is needed. Because the subjects in this study were recruited by convenience sampling, they may not reflect the general population (sampling bias). There is a possibility of sampling bias for evaluating only the subjects who gave consent for this study. The subjects who did not show consent for this study might be in worse or better condition of mental health compared to the participants. Subjective evaluation by the self-administered questionnaires used in this study may be different from objective evaluations. In addition, there is a possibility of recall bias as the subjects answered the questions by looking back on their childhood.

\section{Conclusions}

This study suggests that the quality of parenting is indirectly associated with the PPSR through its effects on neuroticism and perceived job stressors. Reducing neuroticism in children by improving the quality of parenting may reduce job stress in the next generation of workers, and intervention of neuroticism is expected to reduce job stress in the current generation of workers.

\section{Acknowledgments}

This work was partly supported by a Grant-in-Aid for Scientific Research (no. 16K10194 to T. Inoue, and 20K07955 to A. Shimura) from the Japanese Ministry of Education, Culture, Sports, Science and Technology, the Research and Development Grants for Comprehensive Research for Persons with Disabilities from Japan Agency for Medical Research and Development (AMED) to T. Inoue, and SENSHIN Medical Research Foundation to T. Inoue. The authors thank Dr. Nobutada Takahashi of Fuji Psychosomatic Rehabilitation Institute Hospital, Dr. Hiroshi Matsuda of Kashiwazaki Kosei Hospital, Dr. Yasuhiko Takita (deceased) of Maruyamasou Hospital, and Dr. Yoshihide Takaesu of Izumi Hospital for data collection.

\section{Author Contributions}

All authors made substantial contributions to conception and design, acquisition of data, or analysis and interpretation of data; took part in drafting the article or revising it critically for important intellectual content; gave final approval of the version to be published; and agree to be accountable for all aspects of the work.

\section{Disclosure}

Akiyoshi Shimura has received fees from Meiji Seika Pharma, Yoshitomi Yakuhin, Tanabe Mitsubishi Pharma, 
and Eisai outside of the submitted work and is a stockholder of Children and Future Co., Ltd. Jiro Masuya has received personal compensation from Otsuka Pharmaceutical, Eli Lilly, Astellas, and Meiji Yasuda Mental Health Foundation, and grants from Pfizer. Takeshi Inoue has received personal fees from Mochida Pharmaceutical, Takeda Pharmaceutical, Eli Lilly, Janssen Pharmaceutical, MSD, Taisho Toyama Pharmaceutical, Yoshitomiyakuhin, and Daiichi Sankyo; grants from Shionogi, Astellas, Tsumura, and Eisai; and grants and personal fees from Otsuka Pharmaceutical, Dainippon Sumitomo Pharma, Mitsubishi Tanabe Pharma, Kyowa Pharmaceutical Industry, Pfizer, Novartis Pharma, and Meiji Seika Pharma; and is a member of the advisory boards of Pfizer, Novartis Pharma, and Mitsubishi Tanabe Pharma. The other authors declare that they have no actual or potential conflicts of interest.

\section{References}

1. Leka S, Griffiths A, Cox T. Work organisation \& stress: systematic problem approaches for employers, managers and trade union representatives. Protecting workers' health series: no. 3. 2003. Available from: http://www.who.int/occupational_health/publications/en/oehstress.pdf.

2. Virtanen M, Stansfeld SA, Fuhrer R, Ferrie JE, Kivimäki M. Overtime work as a predictor of major depressive episode: a 5-year follow-up of the Whitehall II study. PLoS One. 2012;7:e30719. doi:10.1371/journal.pone.0030719

3. Honkonen T, Ahola K, Pertovaara M, et al. The association between burnout and physical illness in the general population-results from the Finnish Health 2000 Study. J Psychosom Res. 2006;61:59-66. doi:10.1016/j.jpsychores.2005.10.002

4. Ahola K, Väänänen A, Koskinen A, Kouvonen A, Shirom A. Burnout as a predictor of all-cause mortality among industrial employees: a 10-year prospective register-linkage study. J Psychosom Res. 2010;69:51-57. doi:10.1016/j.jpsychores.2010.01.002

5. Karasek R. Job demands, job decision latitude, and mental strain: implication for job resign. Adm Sci Q. 1979;24:285-309. doi:10.2307/2392498

6. Johnson JV, Hall EM. Job strain, work place social support, and cardiovascular disease: a cross-sectional study of a random sample of the Swedish working population. Am J Public Health. 1988;78:1336-1342. doi:10.2105/AJPH.78.10.1336

7. Karasek R, Theorell T. Healthy Work: Stress, Productivity and the Reconstruction of Working Life. New York: Basic Books; 1990.

8. Hurrell JJ, McLaney MA. Exposure to job stress-a new psychometric instrument. Scand J Work Environ Health. 1988;14(Suppl 1):27-28.

9. Kawakami N, Tsutsumi A. The Stress Check Program: a new national policy for monitoring and screening psychosocial stress in the workplace in Japan. J Occup Health. 2016;58:1-6. doi:10.1539/joh.15-0001-ER

10. Haratani T, Kawakami N, Araki S. Reliability and validity of the Japanese version of the NIOSH Generic Job Stress Questionnaire. Jpn J Ind Health. 1993;35:S214.

11. Shimomitsu T, Haratani T, Nakamura K, et al. Final development of the Brief Job Stress Questionnaire mainly used for assessment of the individuals. In: Kato M, editor. The Ministry of Labor Sponsored Grant for the Prevention of Work-Related Illness, FY 1999 Report. Tokyo: Tokyo Medical University; 2000:126-164.
12. Wada K, Sairenchi T, Haruyama Y, Taneichi H, Ishikawa Y, Muto T. Relationship between the onset of depression and stress response measured by the Brief Job Stress Questionnaire among Japanese employees: a cohort study. PLoS One. 2013;8:e56319. doi:10.1371/ journal.pone. 0056319

13. Saijo Y, Chiba S, Yoshioka E, et al. Synergistic interaction between job control and social support at work on depression, burnout, and insomnia among Japanese civil servants. Int Arch Occup Environ Health. 2015;88:143-152. doi:10.1007/s00420-014-0945-6

14. Ando E, Kawakami N, Shimazu A, Shimomitsu T, Odagiri Y Reliability and validity of the English version of the New Brief Job Stress Questionnaire. In: 31st International Conference on Occupational Health; 31 May - 5 June 2015; Seoul, Korea; (Vol.31, pp. 160621).

15. Enns MW, Cox BJ, Larsen DK. Perceptions of parental bonding and symptom severity in adults with depression: mediation by personality dimensions. Can J Psychiatry. 2000;45:263-268. doi:10.1177/ 070674370004500305

16. Kendler KS, Kuhn J, Prescott CA. The interrelationship of neuroticism, sex, and stressful life events in the prediction of episodes of major depression. Am J Psychiatry. 2004;161:631-636. doi:10.1176/ appi.ajp.161.4.631

17. Ono K, Takaesu Y, Nakai Y, et al. Associations among depressive symptoms, childhood abuse, neuroticism, and adult stressful life events in the general adult population. Neuropsychiatr Dis Treat. 2017;13:477-482. doi:10.2147/NDT.S128557

18. Ono Y, Takaesu Y, Nakai Y, et al. The influence of parental care and overprotection, neuroticism and adult stressful life events on depressive symptoms in the general adult population. J Affect Disord. 2017;217:66-72. doi:10.1016/j.jad.2017.03.058

19. Lachowska BH. Neuroticism, work demands, work-family conflict and job stress consequences. Med Pr. 2014;65:387-398.

20. Bianchi R. Burnout is more strongly linked to neuroticism than to work-contextualized factors. Psychiatry Res. 2018;270:901-905. doi:10.1016/j.psychres.2018.11.015

21. Maslach C. Job burnout: new directions in research and intervention. Curr Dir Psychol Sci. 2003;12:189-192. doi:10.1111/14678721.01258

22. Shanafelt T, Goh J, Sinsky C. The business case for investing in physician wellbeing. JAMA Intern Med. 2017;177:1826-1832. doi:10.1001/jamainternmed.2017.4340

23. Parker G, Tupling H, Brown LB. A parental bonding instrument. $\mathrm{Br}$ J Med Psychol. 1979;52:1-10. doi:10.1111/j.2044-8341.1979.tb02487.x

24. Parker G. Parental 'affectionless control' as an antecedent to adult depression. A risk factor delineated. Arch Gen Psychiatry. 1983;40:956-960. doi:10.1001/archpsyc.1983.01790080038005

25. Kessler RC, Magee WJ. Childhood adversities and adult depression: basic patterns of association in a US national survey. Psychol Med. 1993;23:679-690. doi:10.1017/S0033291700025460

26. Wise LA, Zierler S, Krieger N, Harlow BL. Adult onset of major depressive disorder in relation to early life violent victimisation: a case-control study. Lancet. 2001;358:881-887. doi:10.1016/S01406736(01)06072-X

27. Marshall M, Shannon C, Meenagh C, Mc Corry N, Mulholland C. The association between childhood trauma, parental bonding and depressive symptoms and interpersonal functioning in depression and bipolar disorder. Ir $J$ Psychol Med. 2018;35:23-32. doi:10.1017/ipm.2016.43

28. Nakai Y, Inoue T, Toda H, et al. The influence of childhood abuse, adult stressful life events and temperaments on depressive symptoms in the nonclinical general adult population. $J$ Affect Disord. 2014;158:101-107. doi:10.1016/j.jad.2014.02.004

29. Corcoran M, McNulty M. Examining the role of attachment in the relationship between childhood adversity, psychological distress and subjective well- being. Child Abuse Negl. 2018;76:297-309. doi:10.1016/j.chiabu.2017.11.012 
30. Toyoshima K, Inoue T, Masuya J, Ichiki M, Fujimura Y, Kusumi I. Evaluation of subjective cognitive function using the cognitive complaints in bipolar disorder rating assessment (COBRA) in Japanese adults. Neuropsychiatr Dis Treat. 2019;15:2981-2990. doi:10.2147/ NDT.S218382

31. Kitamura T, Suzuki T. A validation study of the Parental Bonding Instrument in a Japanese population. Jpn J Psychiatry Neurol. 1993;47:29-36. doi:10.1111/j.1440-1819.1993.tb02026.x

32. Eysenck S, Eysenck H, Barrett P. A revised version of the psychoticsm scale. Person Individ Diff. 1985;6:21-29. doi:10.1016/01918869(85)90026-1

33. Nakai Y, Inoue T, Toyomaki A, et al. A study of validation of the Japanese version of the shortened Eysenck Personality Questionnaire-Revised. The 35th Congress of Japanese Society for Psychiatric Diagnosis; 2015; Sapporo.

34. Schermelleh-Engel K, Moosbrugger H, Müller H. Evaluating the fit of structural equation model: tests of significance and descriptive goodness-of-fit measures. MPR Online. 2003;8:23-74.

35. Raishevich N, Kennedy SJ, Rapee RM. Expressed emotion displayed by the mothers of inhibited and uninhibited preschool-aged children. J Clin Child Adolesc Psychol. 2010;39:187-194. doi:10.1080/ 15374410903532668
36. Crouter AC, Bumpus MF. Linking parents' work stress to children's and adolescents' psychological adjustment. Curr Dir Psychol Sci. 2001;10:156-159. doi:10.1111/1467-8721.00138

37. Persson R, Høgh A, Grynderup MB, et al. Relationship between changes in workplace bullying status and the reporting of personality characteristics. J Occup Environ Med. 2016;58:902-910. doi:10. 1097/JOM.0000000000000822

38. Armstrong L, Rimes KA. Mindfulness-based cognitive therapy for neuroticism (stress vulnerability): a pilot randomized study. Behav Ther. 2016;47:287-298. doi:10.1016/j.beth.2015.12.005

39. Spinhoven P, Huijbers MJ, Ormel J, Speckens AEM. Improvement of mindfulness skills during Mindfulness-Based Cognitive Therapy predicts long-term reductions of neuroticism in persons with recurrent depression in remission. $J$ Affect Disord. 2017;213:112-117. doi:10.1016/j.jad.2017.02.011

\section{Publish your work in this journal}

Neuropsychiatric Disease and Treatment is an international, peerreviewed journal of clinical therapeutics and pharmacology focusing on concise rapid reporting of clinical or pre-clinical studies on a range of neuropsychiatric and neurological disorders. This journal is indexed on PubMed Central, the 'PsycINFO' database and CAS, and is the official journal of The International Neuropsychiatric Association (INA). The manuscript management system is completely online and includes a very quick and fair peer-review system, which is all easy to use. Visit http://www.dovepress.com/testimonials.php to read real quotes from published authors. 